\title{
Intralymphatic Histiocytosis with Rheumatoid Arthritis: Possible Association with the Joint Involvement
}

\author{
Takahide Kaneko, Sonoko Takeuchi, Hajime Nakano, Daisuke Sawamura \\ Department of Dermatology, Hirosaki University Graduate School of Medicine, Hirosaki, Japan \\ Email: kaneko@cc.hirosaki-u.ac.jp
}

Received 23 January 2014; revised 20 February 2014; accepted 7 March 2014

Copyright (C) 2014 by authors and Scientific Research Publishing Inc.

This work is licensed under the Creative Commons Attribution International License (CC BY). http://creativecommons.org/licenses/by/4.0/

c) (i) Open Access

\begin{abstract}
Intralymphatic histiocytosis is characterized by dilated vessels containing aggregates of mononuclear histiocytes in their lumina, and the majority of cases have been associated with rheumatoid arthritis (RA). We report a case of a 61-year-old woman with RA who presented with livedolike erythema and red papules around the right elbow and forearm. Histological examinations demonstrated numerous dilated vessels in the dermis partially filled with medium- to large-sized mononuclear cells. Immunohistochemically, most of the intraluminal cells were CD68-positive histiocytes. Endothelial cells were positive for D2-40, a marker for lymphatic endothelial cells. We diagnosed the patient with intralymphatic histiocytosis based on these clinical and histological findings. Interestingly, the skin manifestations exacerbated during the course of the disease when the swelling of the patient's right elbow joint progressed. Then, the puncture of content fluid of the joint was performed, since then, the symptoms of the skin lesion immediately improved. These observations suggest a possible association between the eruptions of intralymphatic histiocytosis and the involved joint. The results suggest that such skin eruptions may be ameliorated by treating severe arthritis.
\end{abstract}

\section{Keywords}

Lymphedema; Synovitis; Aspiration

\section{Introduction}

Various dermatoses are associated with rheumatoid arthritis (RA), including rheumatoid nodules, rheumatoid vasculitis, and neutrophilic dermatoses. Intralymphatic histiocytosis is a recently identified RA-associated con- 
dition that manifests clinically as erythematous patches around the joints and histologically as histiocytic aggregations in dilated dermal vessels [1] [2]. We report the case of a 61-year-old woman with RA-associated intralymphatic histiocytosis with an interesting clinical course.

\section{Case Report}

A 61-year-old woman presented with asymptomatic exanthema on her right upper extremity. She stated that the lesion had developed approximately 4 months previously, and had enlarged slowly despite using a topical corticosteroid ointment. Physical examination showed poorly demarcated, slightly indurated livedo-like erythema and red papules with yellowish clear fluid discharge around the right elbow and forearm (Figure 1). She was diagnosed with RA by orthopedic physicians at age of 55, and treated with $5 \mathrm{mg} /$ week methotrexate and 4 $\mathrm{mg} /$ day methylprednisolone. The patient also had a 10-year history of right breast cancer.

Laboratory examinations revealed abnormal C-reactive protein level of $11.0 \mathrm{mg} / \mathrm{dL}$ and erythrocyte sedimentation rate of $134 \mathrm{~mm} / \mathrm{h}$. A biopsy was taken from the skin lesions and the sample was submitted for histological examination. The results showed numerous dilated vessels in the dermis partially filled with medium- to largesized mononuclear cells (Figures 2(a) and (b)). Immunohistochemically, most of the intraluminal cells were CD68-positive histiocytes (Figure 2(c)). The endothelial cells lining the vessels were positive for D2-40, a monoclonal antibody that reacts with lymphatic endothelial cells (Figure 2(d)). However, these endothelial cells were weakly positive for Factor VIII-related antigen and CD34, both of which are specific markers for bloodvessel endothelial cells. The condition was diagnosed as RA-associated intralymphatic histiocytosis based on these clinical and histological manifestations.

During the course of the disease, interestingly, the patient's skin manifestations exacerbated when the swelling of the right elbow joint was observed. Magnetic resonance imaging scans of the right elbow joint revealed RA-associated synovial bursitis. The puncture of content fluid of bursitis was performed, and then the symptoms of the skin lesion immediately improved, despite a lack of dermatologic treatments.

\section{Discussion}

Intralymphatic histiocytosis, first described in 1994, is characterized by dilated vessels containing aggregates of mononuclear histiocytes in their lumina [1]. The majority of cases have been associated with RA [2] [3], although the condition has also been observed after the placement of metal implants and associated with malignant neoplasms [4]-[6]. The most commonly involved sites are the upper extremities, especially around the elbow joint and the lower extremities areoccasionally involved [7]. The skin lesions of intralymphatic histiocyto-

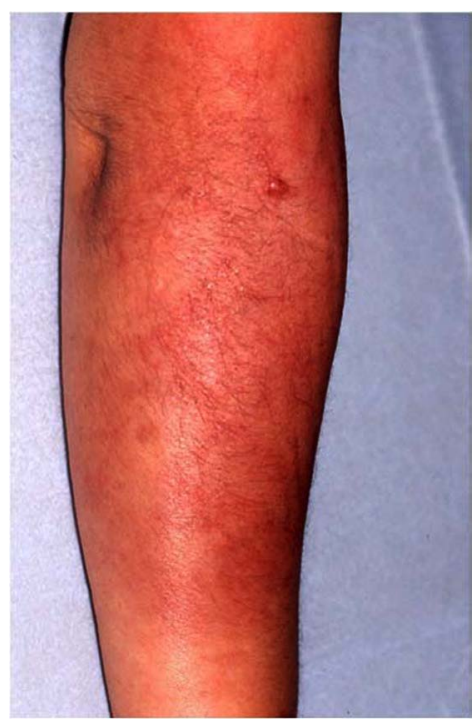

Figure 1. Clinical findings. Poorly demarcated and slight indurated livedo-like erythema and red papules around the right elbow and forearm. 


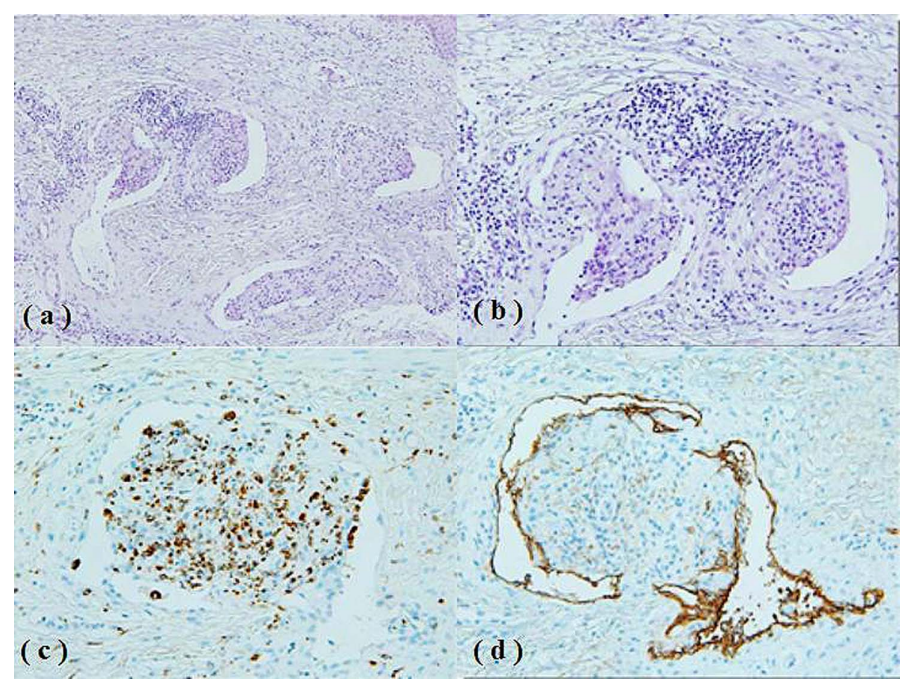

Figure 2. Histological and immunohistochemical findings. (a), (b) Dilated vessels partially filled with medium- to large-sized mononuclear cells in the dermis; (c) Immunohistochemically, most of the intraluminal cells are CD68-positive histiocytes; (d) The endothelial cells lining the vessels are positive for D2- 40, a monoclonal antibody that reacts with lymphatic endothelial cells. (a), (b) $\times 40$, (c), (d) $100 \times$.

sis are asymptomatic with livedo-like erythema, or erythema with confluent papules over or around swollen joints.

Histopathological findings in our patient indicated dilated vessels in the reticular dermis, with a single discontinuous layer of endothelial cells. Some dilated vessels contained aggregates of mononuclear cells. Immunohistochemical studies showed that those intravascular cells were CD68-positive, while the endothelial cells tested positive for D2-40, a marker for lymphatic endothelial cells.

Examination of the patient's clinical findings resulted in differential diagnoses including livedo, cellulitis, lymphangitis, Stewart-Treves syndrome, and erythemaabigne. Histological examination showed characteristic intravascular aggregation of mononuclear cells. Histological differential diagnosis also included intravascular reactive angioendotheliomatosis, intravascular lymphoma, leukemia, and other conditions with intralymphatic collections. Further immunohistochemical examination revealed endothelial cells and intravascular cells that were positive for D2-4 and CD68, respectively. Finally, we diagnosed the condition as intralymphatic histiocytosis.

The pathogenesis of intralymphatic histiocytosis is controversial, and multiple hypotheses have been proposed. Several authors speculate that intralymphatic histiocytosis represents early stage intravascular reactive angioendotheliomatosis [8], whereas others suggest that it is an entirely different disorder because itinvolves lymphatic vessels alone [9]. It has also been suggested that this condition could result from the draining of histiocytes from the joints via the lymphatic system [2] [10]. Standard treatment has not been established. In general, these skin manifestations appear resistant to topical and systemic treatment. On the other hand, spontaneous healing and regression have also been reported [2] [11].

Previous reports showed that the lesions of intralymphatic histiocytosis had a chronic clinical course with an indolent behavior. In cases of association with RA, the clinical course of the cutaneous lesions did not seem parallel to the activity of the joint disease. However, exacerbation of skin symptoms was observed when the involved elbow joint became swollen and painful in our patient. Furthermore, aspiration of fluid from the elbow joint improved not only joint pain and swelling but also the skin symptoms. This suggests that the eruptions of intralymphatic histiocytosis might have a significant relationship to the involved joint, and that treatment of severe arthritis might ameliorate these skin eruptions in some cases.

\section{Conflict of Interest}

Conflict of interest is not declared. 


\section{References}

[1] O’Grady, J.T., Shahidullah, H., Doherty, V.R. and Al-Nafussi, A. (1994) Intravascular Histiocytosis. Histopathology, 24, 265-268. http://dx.doi.org/10.1111/j.1365-2559.1994.tb00519.x

[2] Prium, B., Strutton, G., Congton, S., Whitehead, K. and Donaldson, E. (2000) Cutaneous Histiocytic Lymphangitis: An Unusual Manifestation of Rheumatoid Arthritis. Australasian Journal of Dermatology, 41, 101-105. http://dx.doi.org/10.1046/j.1440-0960.2000.00404.x

[3] Catalina-Fernández, I., Alvárez, A.C., Martin, F.C., Fernández-Mera, J.J. and Sánez-Santamaria, J. (2007) Cutaneous Intralymphatic Histiocytosis Associated with Rheumatoid Arthritis: Report of a Case and Review of the Literature. American Journal of Dermatopathology, 29, 165-168. http://dx.doi.org/10.1097/01.dad.0000251824.09384.46

[4] Watanabe, T., Yamada, N., Yoshida, Y. and Yamamoto, O. (2008) Intralymphatic Histiocytosis with Granuloma Formation Associated with Orthopaedic Metal Implants. British Journal of Dermatology, 158, 402-404. http://dx.doi.org/10.1111/j.1365-2133.2007.08295.x

[5] De Unamuno Bustos, B., García Rabasco, A., Ballester Sánchez, R., Martinez Aparicio, A. and Alegre de Miquel, V. (2013) Erythematous Indurated Plaque on the Right Upper Limb. Intralymphatichistiocytosis (IH) Associated with Orthopedic Metal Implant. International Journal of Dermatology, 52, 547-549. http://dx.doi.org/10.1111/j.1365-4632.2012.05696.x

[6] Echeverría-García, B., Botella-Estrada, R., Requena, C. and Guillén, C. (2010) Intralymphatic Histiocytosis and Cancer of the Colon. Actas Dermo-Sifiliográficas (English Edition), 101, 257-262. http://dx.doi.org/10.1016/S1578-2190(10)70625-9

[7] Okazaki, A., Asada, H., Niizeki, H., Nonomura, A. and Miyagawa, S. (2005) Intravascular Histiocytosis Associated with Rheumatoid Arthritis: Report of a Case with Lymphatic Endothelial Proliferation. British Journal of Dermatology, 152, 1385-1387. http://dx.doi.org/10.1111/j.1365-2133.2005.06618.x

[8] Rieger, E.,Soyer, H.P., Leboit, P.E., Metze, D., Slovak, R. and Kerl, H. (1999) Reactive angioendotheliomatosis or Intravascular Histiocytosis? An Immunohistochemical and Ultrastructual Study in Two Cases of Intravascular Histiocytic Cell Proliferation. British Journal of Dermatology, 140, 497-504. http://dx.doi.org/10.1046/j.1365-2133.1999.02717.x

[9] Requena, L., El-Shabrawi-Caelen, L., Walsh, S.N., Sequra, S., Ziemer, M., Hurt, M.A., Sangüezaet, O.P. and Kutzner, H. (2009) Intralymphatic Histiocytosis. A Clinicopathologic Study of 16 Cases. American Journal of Dermatopathology, 31, 140-151. http://dx.doi.org/10.1097/DAD.0b013e3181986cc2

[10] Grekin, S., Mesfin, M., Kang S. and Fullen, D.R. (2011) Intralymphatic Histiocytosis Following Placement of a Metal Implant. Journal of Cutaneous Pathology, 38, 351-153. http://dx.doi.org/10.1111/j.1600-0560.2010.01556.x

[11] Takiwaki, H., Adachi, A., Kohno, H. and Ogawa, Y. (2004) Intravascular or Intralymphatic Histiocytosis Associated with Rheumatoid Arthritis: A Report of 4 Cases. Journal of the American Academy of Dermatology, 50, 585-590. http://dx.doi.org/10.1016/j.jaad.2003.09.025 